\title{
Baylisascaris procyonis roundworm infection patterns in raccoons (Procyon lotor) from Missouri and Arkansas, USA
}

\author{
H. S. AL-WARID ${ }^{1,2,3}$, A. V. BELSARE' ${ }^{1}$ K. STRAKA ${ }^{4}$, M. E. GOMPPER ${ }^{1}$
}

${ }^{1}$ School of Natural Resources, University of Missouri, 302 Anheuser-Busch Natural Resources Building, Columbia, MO 65211, USA; E-mail: harithalward@scbaghdad.edu.iq, alwaridh@missouri.edu, belsarea@missouri.edu, gompperm@missouri.edu; ${ }^{2}$ Division of Biological Sciences, University of Missouri, 405A Tucker Hall, Columbia, MO 65211, USA; ${ }^{3}$ Department of Biology, College of Science, University of Baghdad Al-Jadriyah, Baghdad, Iraq; ${ }^{4}$ Missouri Department of Conservation, Resource Science Center, 3500 East Gans Road, Columbia, MO 65201, USA, E-mail: StrakaK1@michigan.gov

\section{Article info}

Received September 12, 2016 Accepted January 17, 2017

\begin{abstract}
Summary
Baylisascaris procyonis is a helminth parasite of raccoons Procyon lotor and represents a health concern in paratenic hosts, including humans and diverse domestic and wildlife species. In North America the helminth is expanding its geographic range. To better understand patterns of infection in the Ozark region of the USA, raccoons ( $n=61)$ were collected in 2013-2014 from five counties in Missouri and Arkansas, USA and necropsied. We documented $B$. procyonis in all surveyed locations. The overall prevalence of $B$. procyonis was $44.3 \%(95 \% \mathrm{Cl}=31.9-57.4)$ and was significantly higher in females than males. There were also significant differences in prevalence among raccoons sampled north and south of the Missouri River. Mean intensity was $9.9(\mathrm{Cl}=5.44-17.22)$, and parasites were highly aggregated among hosts such that approximately $20 \%$ of hosts harbor $90 \%$ of parasites. These levels of parasitism indicate that $B$. procyonis is common in the region and its impacts on paratenic hosts could be qualitatively similar to effects observed in other localities.

Keywords: raccoon roundworm; Ascarididae; prevalence; intensity; Missouri; Arkansas
\end{abstract}

\section{Introduction}

The raccoon roundworm, Baylisascaris procyonis (order Ascaridida, superfamily Ascaridoidea), is a parasitic nematode commonly found in the small intestines of raccoons (Procyon lotor) (Kazacos, 2001). Larval stages of $B$. procyonis can cause clinical disease in a variety of paratenic vertebrate hosts, including humans, often resulting in fatal neurologic outcomes (Kazacos, 2001; Graeff-Teixeira et al., 2016). The diversity of wildlife that can become infected and the impact on some populations of hosts is increasingly recognized. For instance, Evans (2002) reported visceral, ocular, and neural larva migrans caused by $B$. procyonis in 26 species of birds and mammals from a single locale in California. Similarly, populations of the Allegheny woodrat (Neotoma magister), a species of conservation concern, are believed to be at risk due to severe population-scale impacts of $B$. procyonis infection (Page, 2013). Raccoons are the definitive host for $B$. procyonis. Although raccoons are distributed across much of North America, $B$. procyonis is principally known from raccoons from the Midwest, Northeast, and West Coast states (Kazacos, 2001; Hernandez et al., 2013). However, the species is increasingly recorded from raccoon populations that were previously assumed to be outside the geographic range (Blizzard et al., 2010; Chavez et al 2012; Pipas et al., 2014). The range expansion of $B$. procyonis into new areas could have impacts on previously-unexposed paratenic host populations or species (Sapp et al., 2016). Such impacts on paratenic hosts populations would likely be dependent on high $B$. procyonis prevalence and infrapopulation sizes; low levels would be less likely to cause population-level effects. Problematically, documentation of the relative size of $B$. procyonis infrapopulations (that is, the inten- 
sity of infection of parasitized hosts; Bush et al., 1997) is poorly known from regions where the parasitic nematode is newly reported. For instance, in Missouri the parasite is known to occur and in Arkansas the parasite has only recently been reported (Monello \& Gompper, 2011; Al-Warid et al., in review), but there is little information on measures of intensity in the region. Understanding the overall pattern of $B$. procyonis prevalence and intensity in a region is a necessary first step in assessing the potential health risks for humans, domestic animals and wildlife.

Intensity information is particularly important because it allows assessment of the extent to which parasites are aggregated within the host population. Parasites often have an aggregated distribution among host individuals, which stabilizes host-parasite population dynamics (Anderson \& May, 1978; Adler \& Kretzscmar, 1992). Previous work on $B$. procyonis in regions the parasite has recently invaded (e.g. Robel et al., 1989; Monello \& Gompper, 2011) have not fully documented the variance in intensity among individual hosts. Yet such variance can be a fundamental tenet of Baylisascaris-raccoon interactions. For instance, Page et al. (2016) included raccoon specimens collected from Missouri as part of a larger study from the Upper Midwest that reported overall prevalence of $36 \%$ and mean intensity of 15.8 , but significant overdispersion such that a relatively small proportion of hosts $(7 \%)$ had larger $(>50)$ B. procyonis infrapopulations. More fully documenting aggregation patterns in raccoons could help formulate a more effective strategy for control of parasite transmission (e.g. Smyser et al., 2015) and predict impacts on paratenic host populations. Thus the objectives of this study were to: 1) investigate the pattern of $B$. procyonis prevalence and intensity in raccoons collected from Missouri and Arkansas, and 2) estimate aggregation indices for $B$. procyonis infection in raccoons.

\section{Materials and Methods}

We obtained 61 raccoons between November 2013 and January 2014, and in November 2014, from five counties in Missouri and one county in Arkansas (Fig. 1). Twenty-eight raccoons from Boone County, Missouri were killed by trappers for pelts, and 33 raccoons were collected by state and federal agency personnel from Cooper, Moniteau and Cole counties (Missouri) and Jefferson County (Arkansas) as a part of an unrelated study.

Raccoon carcasses were processed either fresh or after having been frozen at $-20^{\circ} \mathrm{C}$ for up to 3 months. The sex of each raccoon was recorded and raccoons were classified as adults ( $\geq 12 \mathrm{mo}$ of age) or subadults (<12 mo) based on patterns of tooth emergence and wear. Gastrointestinal tracts were excised, opened longitudinally and nematodes, including late fourth stage B. procyonis, were removed and identified morphologically (Sprent, 1968; Bowman, 1987).

We calculated prevalence as the percent of examined hosts infected by B. procyonis (Bush et al., 1997). Confidence intervals (95\% $\mathrm{Cl})$ for prevalence were calculated using Sterne's exact method in Quantitative Parasitology 3.0 (QP 3.0; Rózsa et al., 2000). Differences in prevalence were examined among sexes, age classes and regions using chi-square and Fisher's exact tests. To assess regional variation, individuals were categorized as deriving from one of three regions: Central Missouri north of the Missouri River (Boone County; $n=28$ ), Central Missouri south of the Missouri River (Cole, Moniteau, Cooper Counties; $n=27$ ), and Northwestern Arkansas (Jefferson County; $n=6$ ).

Intensity was defined following Bush et al. (1997) as the number of $B$. procyonis in an infected host, with $95 \%$ Cls of mean intensity calculated using bootstrap tests ( $n=2000$; Rózsa et al., 2000).

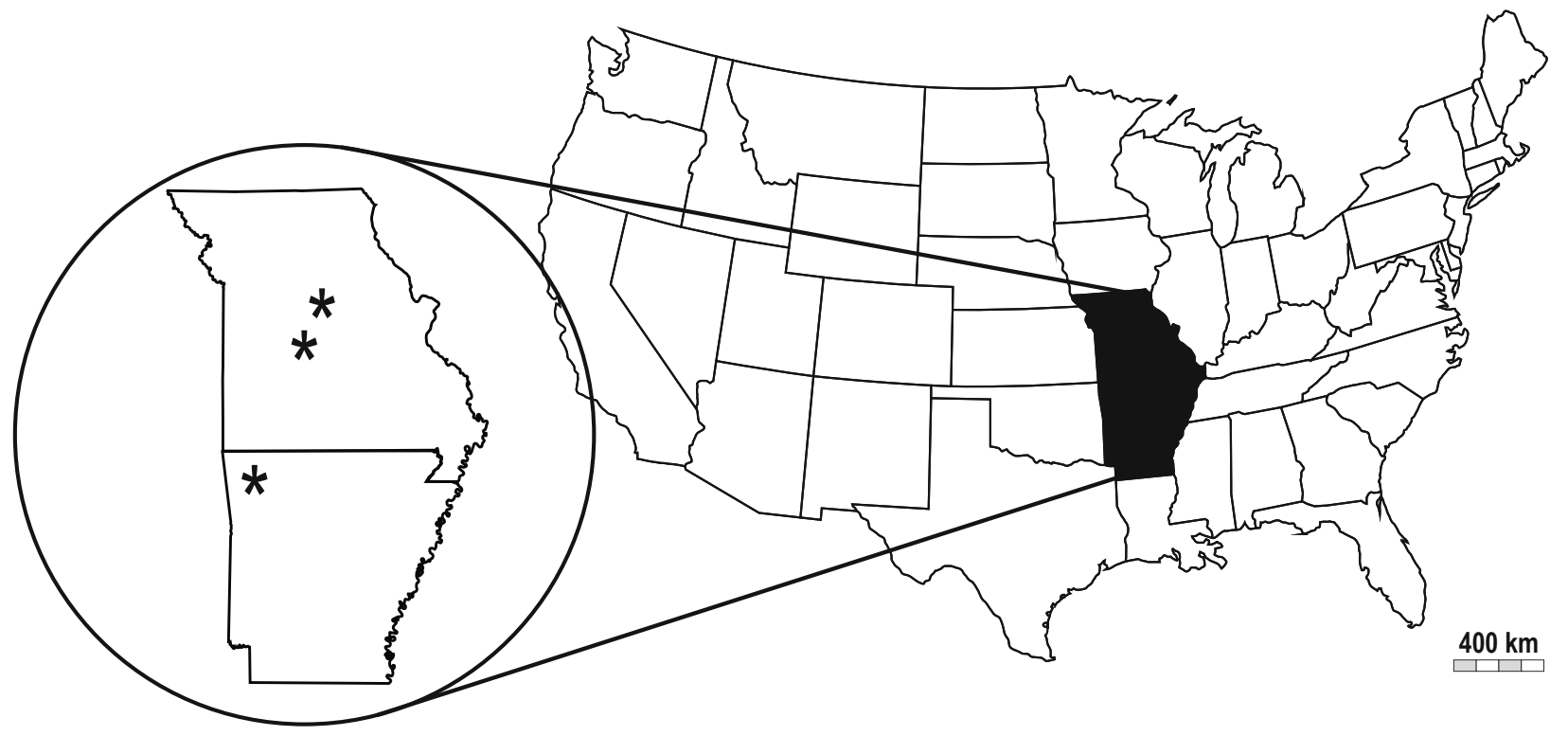

Fig. 1. Map of study sites in the central USA. Asterisks $\left(^{*}\right)$ indicate focal regions for specimen collection in Missouri and Arkansas 
Mean intensity of regions was calculated, but statistical comparisons across regions were conducted using a Mood's median test. Aggregation of $B$. procyonis among hosts was quantified from variance/mean ratios $\left(\mathrm{s}^{2} / \mathrm{m}\right)$ and negative binomial exponent $(\mathrm{k})$ values. All statistical analyses of intensity and aggregation were conducted using QP 3.0 or the online QPweb (http://www2.univet. hu/qpweb/). To assess the relative contribution of differentially infected (or uninfected) hosts to the entire component (sensu Bush et al., 1997) parasite population, infrapopulations (populations of individual hosts) were ranked in decreasing order of abundance, summed, and then converted to a proportion of the component population. This value in turn was contrasted to the proportion of the contributing host population.

\section{Results}

Baylisascaris procyonis occurred in $44.3 \%(\mathrm{Cl}=31.9-57.4)$ of raccoons. Prevalence did not differ (Fisher's Exact test; $p=0.785$ ) among adults $(n=41$; prevalence $=46.3 \% ; C l=31.6-62.3)$ and subadults ( $n=20$; prevalence $=40 \% ; C l=20.9-62.8)$. However, there were differences in prevalence between males and females (Fisher's Exact test; $p=0.032$ ). Prevalence of $B$. procyonis among male raccoons ( $\mathrm{n}=39 ; 33.3 \% ; \mathrm{Cl}=20.3-50.0$ ) was approximately half that of females $(n=22 ; 63.6 \% ; \mathrm{Cl}=41.8-81.3)$. Although samples sizes of demographic cohorts were small and overlap of Cls for prevalence was high across the cohorts, agexsex analyses indicated significant differences $\left(X^{2}=8.183 ; \mathrm{df}=3 ; p\right.$ $=0.042)$ in prevalence among male subadults $(n=9 ; 33.3 \% ; \mathrm{Cl}=$ $9.8-67.7)$, male adults $(n=30 ; 33.3 \% ; \mathrm{Cl}=17.7-51.7)$, female subadults $(\mathrm{n}=11 ; 45.5 \% ; \mathrm{Cl}=20.0-73.5)$ and female adults $(\mathrm{n}=11 ; 81.8 \% ; \mathrm{Cl}=50.0-96.7)$, with high prevalence in adult females likely driving the differences.
Significant differences in prevalence occurred across sampling regions $\left(X^{2}=9.995, d f=2, P=0.007\right)$. Raccoons sampled from Central Missouri south of the Missouri River had higher prevalence $(66.7 \% ; \mathrm{Cl}=46.2-81.9)$ than those sampled from Northwestern Arkansas $(33.3 \% ; \mathrm{Cl}=6.3-72.9)$ and Central Missouri north of the Missouri River counties (25\%; $\mathrm{Cl}=12.0-44.6)$. While the sample size of Northwestern Arkansas animals was small, and thus the $\mathrm{Cl}$ was large and overlapped considerably with the $\mathrm{Cl}$ for raccoons sampled from Central Missouri south of the Missouri River, there was no overlap in the $95 \%$ Cls for prevalence in Missouri raccoons collected north of the Missouri River and those collected south of the river.

Overall mean intensity of $B$. procyonis was $9.9(\mathrm{Cl}=5.4-17.2)$. For subsets of hosts (Table 1), mean intensity did not differ significantly between age classes $(t=0.079$; bootstrap $p=0.939)$ or between the sexes $(t=1.639$; bootstrap $p=0.150)$. There was no statistically significant difference in intensity across regions (Mood's median test; $p=0.688$ ), although intensity south of the Missouri river had high mean intensity $(12.94 ; \mathrm{Cl}=6.44-22.78)$ compared with other regions, and low $\mathrm{Cl}$ overlap with the upper limits of the $95 \% \mathrm{Cl}$ for raccoons analyzed from north of the Missouri river (8.0) (Table 1).

For all raccoons combined, $\mathrm{s}^{2} / \mathrm{m}$ and $\mathrm{k}$ values (29.65 and 0.17 , respectively) indicated that $B$. procyonis was highly aggregated among hosts (Fig. 2). Relatively few hosts harbored a large proportion of the parasite population. Ranked infrapopulations indicate the six most heavily infected hosts $(9.8 \%$ of examined hosts; range in parasites per host $=16-54$ ) harbored $77.5 \%$ of the B. procyonis component population, and $20 \%$ of hosts harbored $90 \%$ of parasites (Fig. 3). Excluding uninfected hosts, $22 \%$ of hosts were parasitized by $76 \%$ of $B$. procyonis. Similar patterns of parasite aggregation held for host subsets (males, females, adults,

Table 1. Baylisascaris procyonis prevalence and mean (median for primary subsets in parentheses) intensity, with $95 \%$ confidence interval of mean derived from 2000 bootstrap iterations, for all raccoons examined as well as subsets of the total population.

\begin{tabular}{lcccc}
\hline Population & $\mathbf{n}$ & $\mathbf{n}$ infected (\%) & $\begin{array}{c}\text { Mean intensity } \\
\text { (median) }\end{array}$ & $\mathbf{9 5 \% C l}$ \\
\hline all & 61 & $27(44.3)$ & $9.89(3)$ & $5.33-17.04$ \\
adults & 41 & $19(46.3)$ & $10.05(3)$ & $5.05-20.32$ \\
subadults & 20 & $8(40)$ & $9.5(3)$ & $2.50-29.13$ \\
females & 22 & $14(63.6)$ & $14.36(3.5)$ & $6.43-27.57$ \\
males & 39 & $13(33.3)$ & $5.08(2)$ & $2.23-10.31$ \\
adult females & 11 & $9(81.8)$ & 14.56 & $4.33-31.00$ \\
adult males & 30 & $10(33.3)$ & 6 & $2.30-12.20$ \\
subadult females & 11 & $5(45.5)$ & 14 & $2.80-41.00$ \\
subadult males & 9 & $3(33.3)$ & 2 & - \\
North of Missouri River & 28 & $7(25)$ & $4.14(2)$ & $2.14-8.00$ \\
South of Missouri River & 27 & $18(66.7)$ & $12.94(3)$ & $6.50-23.28$ \\
Arkansas & 6 & $2(33.3)$ & $2.5(2.5)$ & - \\
\hline
\end{tabular}




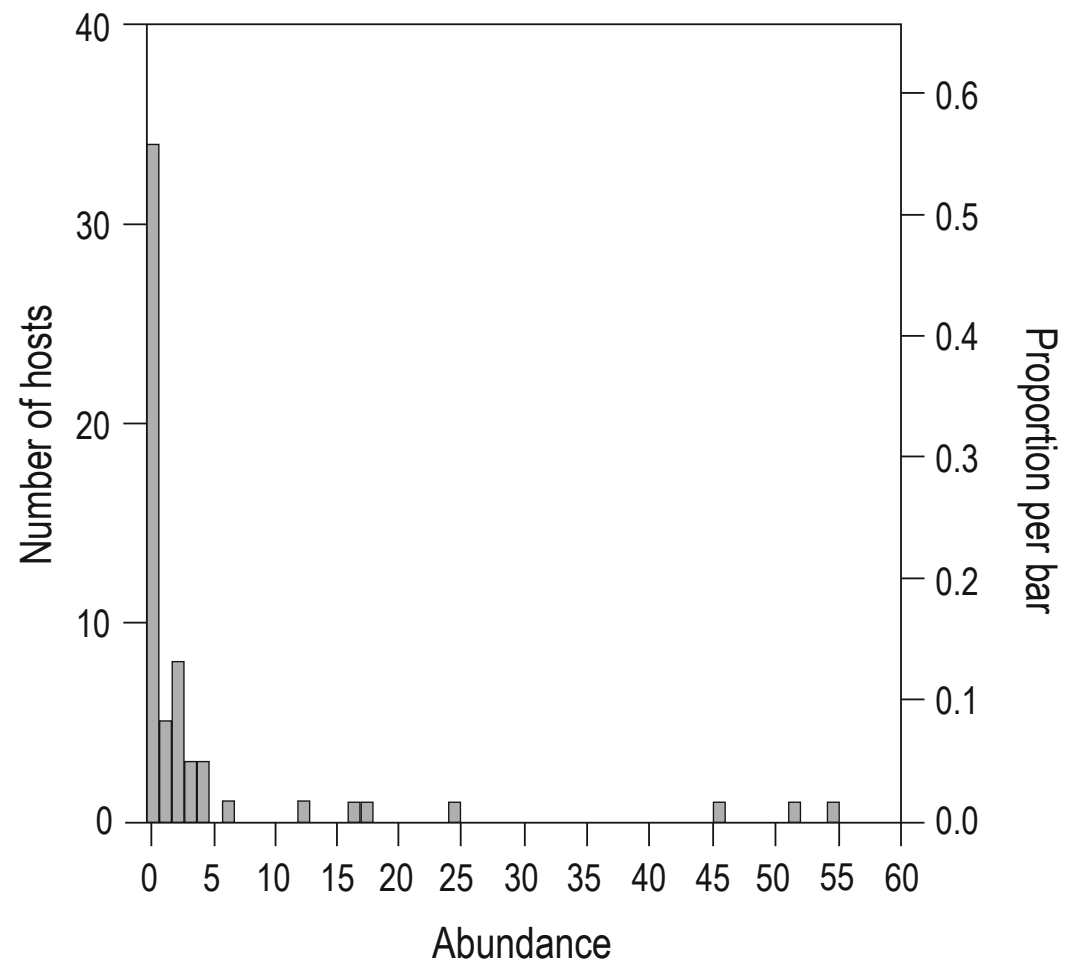

Fig. 2. Distribution of Baylisascaris procyonis abundance (number of parasites per host, including uninfected hosts) among $n=61$ raccoons examined from Missouri and Arkansas

subadults, north of the Missouri river, south of the Missouri river); in each case there was a high level of aggregation of $B$. procyonis among hosts (Table 2). Although aggregation was greater in females than males, and south of the Missouri river compared to north of the Missouri river, in all cases the negative binomial exponents $(k)$, were generally consistent with a negative binomial distribution, and in all subsets with sufficient sample sizes, the distributions were not significantly different from those predicted by the negative binomial distribution ( $p$-values from $\mathrm{X}^{2}$ tests were $>0.05$ ).

\section{Discussion}

Baylisascaris procyonis has been reported from Missouri (Monello
\& Gompper, 2011; Page et al., 2016). Prevalence in central Missouri based on fecal surveys was $9-20 \%$, with the variance a function of the study population (Monello \& Gompper, 2011). However, no detailed assessments of the prevalence or intensity of parasitism by $B$. procyonis based on necropsies has been previously published for the region. Further, previous work on raccoon endoparasite communities in Arkansas conducted in the 1980s and 1990s failed to identify the presence of $B$. procyonis (Richardson et al., 1992), which suggests the parasite may be spreading in the region. However, the detection of the parasite in Arkansas is not unexpected, as the species has been reported from most surrounding states (Hernandez et al., 2013). Although low numbers of raccoons were collected and only five counties surveyed from the two states,

Table 2. Aggregation metrics for Baylisascaris procyonis across all raccoons as well as subsets of raccoons. Higher variance/mean ( $\left.\mathrm{s}^{2} / \mathrm{m}\right) \mathrm{ratios}$, and lower $\mathrm{k}$ values indicate an increasingly skewed distribution of parasites and increasing concentration of parasites in fewer individual hosts. Host collected from Arkansas are excluded as a distinct subset because of small sample size $(n=6)$.

\begin{tabular}{lccc}
\hline Population & $\mathbf{n}$ & $\mathbf{s}^{2} / \mathbf{m}$ & $\boldsymbol{k}$ \\
\hline All & 61 & 29.65 & 0.1721 \\
Males & 39 & 12.79 & 0.1664 \\
Females & 22 & 32.23 & 0.2665 \\
Adults & 41 & 28.34 & 0.6163 \\
Subadults & 20 & 34.56 & 0.1466 \\
North of Missouri River & 28 & 6.4 & 0.1381 \\
South of Missouri River & 27 & 29.96 & 0.2876 \\
\hline
\end{tabular}




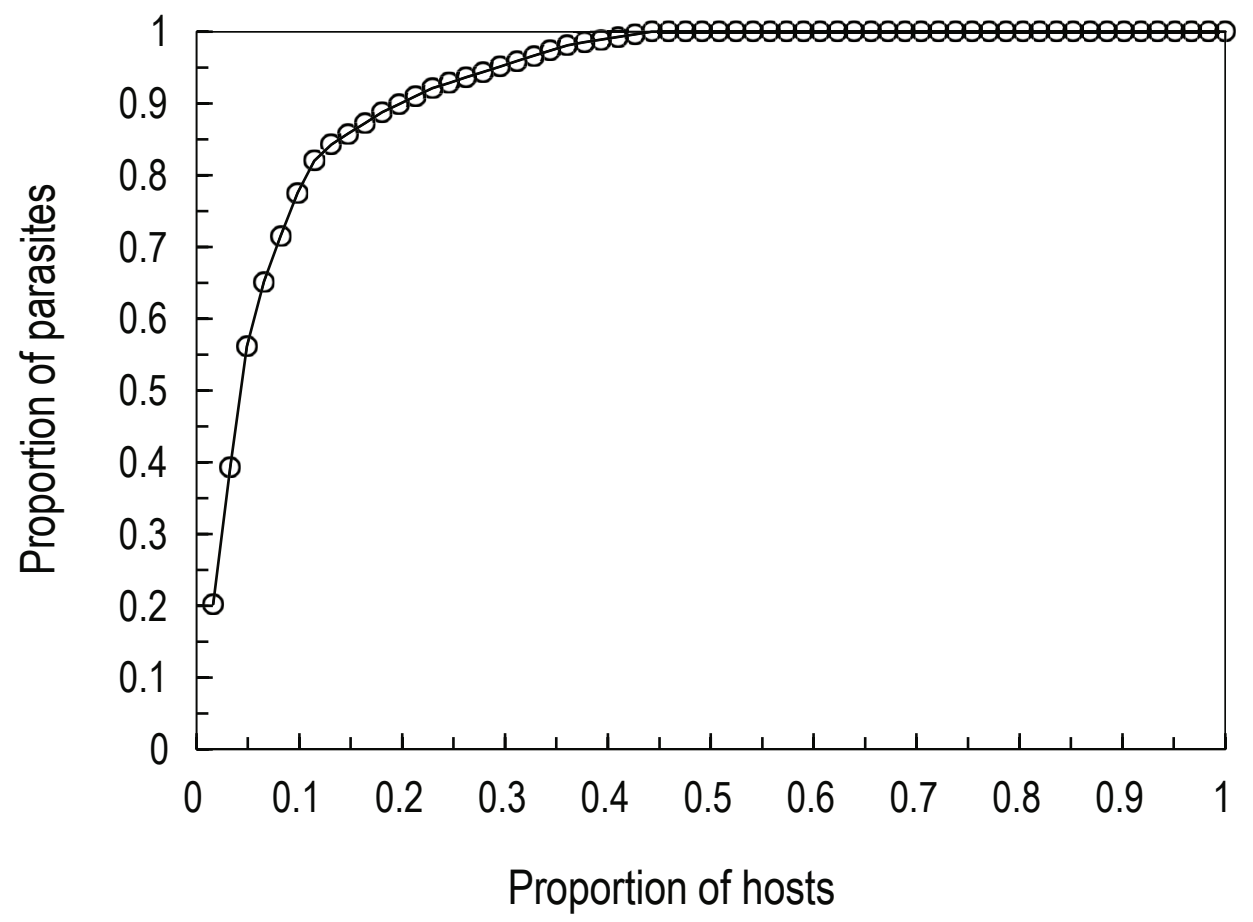

Fig. 3. Relationship between the proportion of hosts examined $(n=61)$ and the proportion of the total parasite component population $(n=267)$. Hosts are included irrespective of infection status, and are ranked in order of decreasing infrapopulation size (abundance). Approximately $20 \%$ of the examined host population was inhabited by approximately $90 \%$ of the parasite population

these results suggest the parasite is likely widespread in the region. The raccoons examined in this study were all collected between the months of November 2013 and January 2014, as well as during November 2014. Page et al. (2016) have shown strong seasonal variation in infrapopulation size of $B$. procyonis in the Midwestern US, with peaks in prevalence and intensity during approximately October - January. Similar patterns have been observed by Kidder et al. (1989) in New York. If such seasonal patterns also occur in the regions of Missouri and Arkansas, than our rates of observed prevalence and intensity are likely not biased downwards due to sample collection during warmer months when rates of parasitism tend to be lower. The overall prevalence observed in this study (44\%) was similar to the $36 \%$ prevalence observed by Page et al. (2016). We did observe significant differences in prevalence in populations separated by the Missouri River. Such strong site-specific or fine-scale differences in the extent of parasitism are widespread in parasitology (Gibson et al., 2016) and have been reported for $B$. procyonis in Kansas (Robel et al., 1989). These patterns may be influenced by ecological factors such as habitat characteristics, and raccoon densities or contact rates (Gompper \& Wright, 2005; Monello \& Gompper, 2011).

The mean intensity observed in this study $(9.9 ; \mathrm{Cl}=5.44-17.22)$ was similar to that $(15.8 ; 13.4$ - 18.3) observed by Page et al. (2016). While we observed statistically significant differences in prevalence as a function of host sex and host source, such patterns were not observed for mean intensity of $B$. procyonis. This lack of robust differences in intensity when subsets of individuals were contrasted may be a function of the high rates of aggregation of parasites among hosts. While prevalence rates were relatively high, most $(70 \%)$ infrapopulations were comprised of $\leq 4$ nematodes. In contrast, a small proportion of hosts were associated with a disproportionate number of parasites. For instance, the three most heavily infected individuals (representing $11 \%$ of infected hosts and $5 \%$ all hosts) accounted for $56 \%$ of the observed parasite population. These high rates of aggregation were also observed (Table 2) when the total host population was subdivided into demographic or regional subpopulations.

Although the sample sizes of raccoons analyzed in this study are comparatively small, the resulting data allow us to emphasize several important points regarding $B$. procyonis. First, the relatively high collective rates of prevalence and intensity indicate that $B$. procyonis is common in the study region(s) and therefore the impact of this parasite on paratenic hosts including humans, domestic animals, and wildlife species may be qualitatively similar to effects observed in other locales. Second, the observed patterns of aggregation suggest the potential to use experimental and observational approaches to assess which demographic and environmental characteristics of individual raccoons best predict infection status (e.g. Monello \& Gompper, 2011; Ruiz-Lopez et al., 2014). Such analyses are an important step in undertaking informed parasite management. 


\section{Acknowledgements}

This work was facilitated by the logistic support of the Missouri Department of Conservation. The manuscript was improved based on comments of two anonymous reviewers.

\section{References}

Adler, F. R., Kretzschmar, M. (1992): Aggregation and stability in parasite-host models. Parasitology, 104: 199 - 205. DOI: http:// dx.doi.org/10.1017/S0031182000061631

Anderson, R. M., May, R. M. (1978): Regulation and stability of host-parasite population interactions: I. Regulatory processes. J. Anim. Ecol., 47: 219 - 247. DOI: 10.2307/3933

Blizzard, E.L., Davis, C.D., Henke, S., Long, D.B., Hall, C.A., YaBSLEY, M.J. (2010): Distribution, prevalence, and genetic characterization of Baylisascaris procyonis in selected areas of Georgia. J. Parasitol., 96: 1128 - 1133. DOI: 10.1645/GE-2518.1

Bowman, D. D. (1987): Diagnostic morphology of four larval ascaridoid nematodes that may cause visceral larva migrans: Toxascaris leonina, Baylisascaris procyonis, Lagochilascaris sprenti, and Hexametra leidyi. J. Parasitol., 73: 1198 - 1215. DOI: $10.2307 / 3282306$

Bush, A. O., Lafferty, K. D., Lotz, J. M., Shostak, A. W. (1997): Parasitology meets ecology on its own terms: Margolis et al., revisited. J. Parasitol., 83: 575 - 583. DOI: 10.2307/3284227

Chavez, D. J., LeVan, I. K., Miller, M. W., Ballweber, L. R. (2012): Baylisascaris procyonis in raccoons (Procyon lotor) from eastern Colorado, an area of undefined prevalence. Veterinary Parasitol., 185: 330 - 334. DOI: 10.1016/j.vetpar.2011.11.002

Evans, R. H. (2002): Baylisascaris procyonis (Nematoda: Ascarididae) larva migrans in free-ranging wildlife in Orange County, California. J. Parasitol., 88: 299 - 301. DOI: http://dx.doi. org/10.1645/0022-3395(2002)088[0299:BPNALM]2.0.CO;2

GiBSON, A. K., JokelA, J., AND Lively, C. M. (2016): Fine-scale spatial covariation between infection prevalence and susceptibility in a natural population. Amer. Nat., 188: 1 - 14. DOI: 10.1086/686767 Gompper, M. E., WRIGHT, A. N. (2005): Altered prevalence of raccoon roundworm (Baylisascaris procyonis) owing to manipulated contact rates of hosts. J. Zool., 266: 215 - 219. DOI: 10.1017/ S0952836905006813

Graeff-Teixeira, C., Morassutti, A. L., Kazacos, K. R. (2016): Update on baylisascariasis, a highly pathogenic zoonotic infection. Clin. Microbiol. Rev., 29: 375 - 399. DOI: 10.1128/CMR.00044-15. Hernandez, S. M., Galbreath, B., Riddle, D. F., Moore, A. P., Palamar, M. B., Levy, M. G., Deperno, C., Correa, M. Yabsley, M. J. (2013): Baylisascaris procyonis in raccoons (Procyon lotor) from North Carolina and current status of the parasite in the USA. Parasitol. Res., 112: 693 - 698. DOI: 10.1007/s00436-012-3186-1
KaZACos, K.R. (2001): Baylisascaris procyonis and related species. In: Samuel, W. M., Pybus, M. J., Kocan, A. A. (Eds) Parasitic Diseases of Wild Mammals. 2nd ed. Ames, lowa: lowa State University Press, pp. 301-341

Kidder, J. D., Wade, S. E., Richmond, M. E., Schwager, S. J. (1989): Prevalence of patent Baylisascaris procyonis infection in raccoons (Procyon lotor) in Ithaca, New York. J. Parasitol., 75: 870 - 874. DOI: $10.2307 / 3282865$

Monello, R. J., Gomprer, M. E. (2011): Effects of resource availability and social aggregation on the species richness of raccoon endoparasite infracommunities. Oikos, 120: 1427 - 1433. DOI: 10.1111/j.1600-0706.2011.19260.x

PAGE, L. K. (2013): Parasites and the conservation of small populations: The case of Baylisascaris procyonis. Int. J. Parasitol: Parasites and Wildl., 2: 203 -210. DOI: 10.1016/j.jpppaw.2013.05.003 Page, L. K., Delzell, D. A., Gehrt, S. D., Harrell, E. D., Hiben, M., Walter, E., Anchor, C. Kazacos, K. R. (2016): The structure and seasonality of Baylisascaris procyonis populations in raccoons (Procyon lotor). J. Wildl. Dis., 52: 286 - 292. DOI: 10.7589/201506-153

Pipas, M. J., Page, L. K., Kazacos, K. R. (2014): Surveillance for Baylisascaris procyonis in raccoons (Procyon lotor) from Wyoming, USA. J. Wildl. Dis., 50: 777 - 783. DOI: 10.7589/2013-10263

Richardson, D. J., Owen, W. B., Snyder, D. E. (1992): Helminth parasites of the raccoon (Procyon lotor) from north-central Arkansas. J. Parasitol., 78: 163 - 166. DOI: 10.2307/3283710

Robel, R. J., Barnes, N. A., Upton, S. J. (1989): Gastrointestinal helminths and protozoa from two raccoon populations in Kansas. J. Parasitol., 75: 1000 - 1003. DOI: $10.2307 / 3282888$

Rózsa L., Reiczigel J., Majoros G. (2000): Quantifying parasites in samples of hosts. J. Parasitol., 86: 228 - 232. DOI: 10.1645/0022-3395(2000)086[0228:QPISOH]2.0.CO;2

Ruiz-López, M. J., Monello, R. J., Schuttler, S. G., Lance, S. L., Gompper, M. E., Eggert, L. S. (2014): Major Histocompatibility Complex, demographic, and environmental predictors of antibody presence in a free-ranging mammal. Infect. Gen. Evol., 28: 317 327. DOI: 10.1016/j.meegid.2014.10.015

Sapp, S. G., Weinstein, S. B., McMahan, C. S., Yabsley, M. J. (2016): Variable Infection dynamics in four Peromyscus species following experimental inoculation with Baylisascaris procyonis. J. Parasitol., 102: 538 - 544. DOI: 10.1645/16-57

Smyser, T. J., Johnson, S. R., Stallard, M. D., McGrew, A. K., Page, L. K., Crider, N., Ballweber, L. R., Swihart, R. K., VerCauteren, K. C. (2015): Evaluation of anthelmintic fishmeal polymer baits for the control of Baylisascaris procyonis in free-ranging raccoons (Procyon lotor). J. Wildl. Dis., 51: 640 - 650. DOI: 10.7589/2014-09-236 SPRENT, J.F. (1968): Notes on Ascaris and Toxascaris, with a definition of Baylisascaris gen. nov. Parasitology, 58: 185 - 198. DOI: $10.1017 /$ S0031182000073534 